\title{
Colon capsule endoscopy: Detection of colonic polyps compared with conventional colonoscopy and visualization of extracolonic pathologies
}

\author{
Alexander F Hagel $\mathrm{MD}^{1^{*}}$, Erwin Gäbele $\mathrm{MD}^{2^{*}}$, Martin Raithel $\mathrm{MD}^{1}$, Wolfgang $\mathrm{H}$ Hagel $M D^{1}$, Heinz Albrecht $\mathrm{MD}^{1}$, \\ Thomas $M$ de Rossi $M D^{1}$, Christine Singer $M^{3} D^{3}$, Thomas Schneider $M D^{4}$, Markus F Neurath $M D^{1}$, Michael J Farnbacher $M D^{4}$

\begin{abstract}
AF Hagel, E Gäbele, M Raithel, et al. Colon capsule endoscopy: Detection of colonic polyps compared with conventional colonoscopy and visualization of extracolonic pathologies. Can J Gastroenterol Hepatol 2014;28(2):77-82.
\end{abstract} \\ La vidéo-capsule endoscopique du côlon : la \\ détection des polypes du côlon par rapport à la \\ coloscopie classique et à la visualisation des \\ pathologies extracoliques
}

BACKGROUND: Conventional colonoscopy (CC) is the gold standard for diagnostic examination of the colon. However, the overall acceptance of this procedure is low due to patient fears of complications or embarrassment. Colon capsule endoscopy (CCE) represents a minimally invasive, patient-friendly procedure that offers complete visualization of the entire intestine.

OBJECTIVE: To assess the PillCam Colon 2 (Given Imaging Ltd, Israel) capsule with regard to feasibility, sensitivity and specificity for the detection of colonic pathologies and additional recorded extracolonic findings.

METHODS: CCE was performed before CC in patients indicated for $\mathrm{CC}$ for known or suspected colonic disease. The results of both techniques were compared with regard to polyp detection. Additionally, bowel preparation and extracolonic pathologies were analyzed.

RESULTS: Twenty-four patients (mean age 51.1 years) were included in the analysis. Visualization of the colon was complete in $23 \mathrm{CCs}$ and 17 CCEs. No adverse events or major technical failures occurred. CC detected 47 polyps and CCE detected 43 polyps of any size (per-finding sensitivity $90.9 \%$, specificity $67.6 \%$ ). The accuracy of CCE in detecting polyp carriers was $81.5 \%$ (per-patient analysis). On average, the colon was adequately cleansed in $90.1 \%$ of patients. CCE identified esophageal, gastric and small bowel pathologies in seven (24\%), nine (38\%) and $14(58 \%)$ patients, respectively.

CONCLUSIONS: CCE proved to be technically feasible and safe. Acceptable sensitivity and moderate specificity levels in polyp detection were recorded. Bowel preparation was adequate in most patients. Because extracolonic pathologies were effectively visualized, new indications for the PillCam Colon 2 may be defined.

Key Words: Cancer prevention; Capsule endoscopy; Colon; Colonoscopy; Colorectal cancer

Colon cancer represents one of the most common malignancies, with an incidence of 15 to 45 per 100,000 per year (1). Consequent identification and removal of adenomatous polyps during colonoscopy has been shown to be highly effective in cancer prevention (2). However, the most important limiting factor of screening colonoscopy is the limited adherence by the screening population, which arises from its invasiveness, discomfort, embarrassment for the patient and the need for bowel preparation (3), resulting in lower screening rates compared with other screening programs (eg, breast and prostate cancer) (4).

Noninvasive diagnostic techniques, such as colon capsule endoscopy (CCE), have proven to be one alternative to increase uptake of endoscopic colorectal cancer (CRC) screening (5).
HISTORIQUE : La coloscopie classique (CC) est la référence pour
l'examen diagnostique du côlon. Cependant, l'acceptation globale de
cette intervention est peu élevée en raison de la peur de complications
ou de l'embarras. La vidéo-capsule endoscopique du côlon (VCEC) est
une intervention peu invasive et facile à accepter pour le patient, qui
permet de visualiser l'ensemble de l'intestin. OBJECTIF : Évaluer la faisabilité, la sensibilité et la spécificité de la capsule PillCam Colon 2 (Given Imaging Ltd, Israël) pour déceler les pathologies du côlon et saisir d'autres observations extracoliques.

MÉTHODOLOGIE : La VCEC a été effectuée avant la CC chez les patients devant effectuer une $\mathrm{CC}$ en raison d'une maladie colique connue ou présumée. Les chercheurs ont comparé les résultats des deux techniques pour déceler des polypes. De plus, ils ont analysé la préparation intestinale et les pathologies extracoliques.

RÉSULTATS : Vingt-quatre patients (âge moyen de 51,1 ans) ont participé à l'analyse. La visualisation du côlon était complète dans 23 CC et 17 VCEC. Aucun événement indésirable ou échec technique majeur ne s'est produit. La CC a permis de déceler 47 polypes et la VCEC, 43 polypes de toute dimension (sensibilité de 90,9\% par détection, spécificité de 67,6\%). La précision de la VCEC à déceler les porteurs de polypes s'établissait à 81,5\% (analyse par patient). En moyenne, le côlon était bien nettoyé chez 90,1 \% des patients. La VCEC a permis de dépister des pathologies œsophagienne, gastrique et du grêle chez sept (24\%), neuf (38\%) et 14 (58\%) patients, respectivement.

CONCLUSIONS : La VCEC s'est révélée sécuritaire et faisable sur le plan technique. On a signalé un taux de sensibilité acceptable et de spécificité modérée dans la détection des polypes. La préparation intestinale était adéquate chez la plupart des patients. Puisque la visualisation des pathologies extracoliques était efficace, de nouvelles indications pourraient être définies pour la capsule PillCam Colon 2.

The PillCam Colon (Given Imaging Ltd, Israel) represented the first such noninvasive diagnostic tool for CRC screening. However, the diagnostic yield of its first-generation model introduced in 2006 was rather inadequate, with a sensitivity of $71 \%$ and specificity of $75 \%$ (6). Consequently, an improved second-generation model - PillCam Colon 2 - was developed. In two large multicentre studies, notably improved sensitivity rates of $85 \%$ to $89 \%$, and specificity rates of $64 \%$ to $95 \%$ were reported in per-patient analyses $(7,8)$.

The primary aim of our study was to evaluate the sensitivity of PillCam Colon 2 for the detection of colonic polyps compared with conventional colonoscopy (CC). As a secondary aim, all visualized extracolonic findings were recorded.

\footnotetext{
*Authors who contributed equally to the manuscript

${ }^{1}$ Department of Gastroenterology, University of Erlangen; ${ }^{2}$ Department of Gastroenterology, Asklepios Clinic Burglengenfeld, Burglengenfeld; ${ }^{3}$ Institute of Employment Research, Nuremberg; ${ }^{4}$ Department of Gastroenterology, Clinical Centre Fuerth, Teaching Hospital of the University of Erlangen, Erlangen, Germany

Correspondence: Dr Michael J Farnbacher, Department of Gastroenterology, Clinical Centre Fuerth, Jakob-Henle-Str. 1, Fuerth 91058 , Germany. Telephone 0049-911-7580-1151, fax 0049-9131-7580-1888, e-mail farnbacher.denkes@t-online.de
} 


\begin{tabular}{ll} 
TABLE 1 & \\
Colon cleansing regimen & \\
\hline Schedule & Intake \\
\hline Day 1 & \\
$\quad$ Evening & 4 senna tablets \\
Day 2 & \\
All day & Liquid diet \\
$\quad$ Afternoon & 2 L PEG \\
Capsule examination day/day 3 & \\
Early morning (05:00) & 2 L PEG \\
$09: 00$ & Capsule ingestion \\
Capsule in small bowel & $30 \mathrm{~mL} \mathrm{NaP}$ and $1 \mathrm{~L}$ water \\
$3 \mathrm{~h}$ after first boost (If no capsule egestion & $15 \mathrm{~mL} \mathrm{NaP}$ and $0.5 \mathrm{~L}$ water \\
$\quad$ has occurred) & \\
$2 \mathrm{~h}$ after second boost (If no capsule egestion & $10 \mathrm{mg}$ bisacodyl as \\
$\quad$ has occurred) & suppository \\
Evening & $2 \mathrm{~L} \mathrm{PEG}$ \\
Colonoscopy examination day/day 4 & \\
10:00 & Colonoscopy \\
\hline
\end{tabular}

PEG Polyethylene glycol; NaP Sodium phosphate

\section{METHODS}

Second-generation CCE, which was used exclusively in the present study, has improved hardware and software compared with its predecessor. Both cameras have an increased angle of $172^{\circ}$ (compared with $156^{\circ}$ in the first generation) to enable nearly $360^{\circ}$ coverage of the colon. Furthermore, the frame rate has been changed from a stable rate of 4 images/s to a variable rate of 4 images/s to 35 images/s depending on capsule propulsion. To increase battery life span, the first generation was inactive during the first $1 \mathrm{~h} 45 \mathrm{~min}$ of deployment, which resulted in missed examination of the cecum in a minority $(9.8 \%)$ of cases $(9)$. To prevent this possible disadvantage, second-generation CCE does not become completely inactive but only transmits 14 images/min while in the stomach and switches to the normal examination rate of 4 images $/ \mathrm{s}$ to 35 images/s after automatic identification of the small bowel (SB). Alternatively, this automatically steered frame rate can be manually activated by the examiner at any time. The latter enables physicians to examine the entire intestine, if necessary; however, in this setting, automatic detection of the $\mathrm{SB}$ is disabled.

To facilitate capsule propulsion, reduce colonic transit times and, subsequently, increase the chance of complete capsule colonoscopies, additional doses of sodium phosphate boosters were administered after capsule ingestion. The appropriate moment for boost administration is indicated visually and acoustically by the data recorder of the capsule system after automatic detection of SB mucosa.

Because CC represents the gold standard for diagnosing colonic pathologies, all patients underwent this procedure the day after CCE.

\section{Patient characteristics}

Twenty-four patients who were scheduled to undergo CC for known or suspected colonic diseases were included in the present study. Indications included CRC screening, personal or family history of $\mathrm{CRC}$ or adenomatous polyps, with no previous colonoscopy within three years. Exclusion criteria were swallowing disorders, congestive heart failure, contraindication for the laxatives used in the study, pregnancy or implanted cardiac devices. All patients gave written consent to participate in the present study, which was conducted according to the Declaration of Helsinki. Approval of the institutional review board was obtained.

\section{Cleansing and administration of CCE}

A typical cleansing regimen was used (Table 1). In all cases, CCE was performed first, followed by CC the day after. During the day of CCE, two boosts (the second boost administered if no capsule egestion occurred) consisting of sodium phosphate were administered, followed by additional laxative (if no egestion occurred) to accelerate capsule propulsion and ensure adequate bowel preparation for endoscopy. This two-day regimen was scheduled to avoid any interference with CCE as described in previous studies (8).

\section{Standardized video reading}

The recorded CCE videos were interpreted by two investigators who are highly experienced with SB capsule endoscopy and specifically trained for CCE. Video recording was performed using the RAPID version 7 software (Given Imaging Ltd, Israel) and standardized using the following protocol. A combination of sharpness level (grade 3) and brightness level (grade 0) was used as a standard baseline to enhance all images (Quick Adjust settings). After defining the essential anatomical landmarks (first and last cecal images, hepatic and splenic flexures, first and last rectal images) the entire video was read in the normal mode using single-head viewing. Thumbnail images of all polyp findings were taken. Reading velocity in this 'cruise and capture' phase was 5 frames/s to 6 frames/s. If necessary, manual frame-by-frame viewing was performed. Then, the correct number of polyps was defined and confirmed in double-head viewing. Polyp size was measured using the polyp size estimation tool of the RAPID 7 software. If multiple frames showed the finding, the biggest diameter was adopted into the analysis.

Reading of extracolonic segments of capsule videos was performed by single-head viewing only. Viewing was routinely started with the green head. To assess the value of PillCam Colon 2 in presenting extracolonic findings, the esophageal transit time, as well as the durations of gastric and SB video sequences, were measured. Additionally, the visualization of anatomical landmarks (esophagogastric junction, pylorus, papilla of Vater and ileocecal valve) as well as esophageal, gastric and SB cleanliness using a four-point grading scale and, finally, pathological as well as physiological findings, were recorded.

To assess the quality of colon preparation, a previously described four-point grading scale (excellent, good, fair, poor) was used (9). Using this grading scale, fair and poor conditions represented inadequate cleansing not enabling complete evaluation of the colonic mucosa. Adequate preparation was recorded if cleanliness enabled the reader to detect polyps $\geq 5 \mathrm{~mm}$ in size, as suggested by Leighton and $\operatorname{Rex}(10)$.

CC was performed by experienced endoscopists in all cases. Colonoscopists were blinded to the capsule reader's results. In case of a CCE-reported finding missed during CC, the endoscopist was unblinded with respect to this finding only.

\section{Statistical methods}

Patient age, sex, colon cleanliness, adverse events, transit times and completeness of examinations were recorded. Matching of colonic polyps recorded in CCE and flexible colonoscopy was performed by comparison of size, location and morphology. Matching of the size was determined if the size measured in CC (visually compared with the open forceps or to the pathology report if snare polypectomy had been performed) was within $50 \%$ of its reference standard measure at CCE.

The primary end point of the study was the accuracy of CCE versus $\mathrm{CC}$ in identifying colorectal polyps. For this per-finding analysis, polyps were divided into three subgroups according to their size $(<6 \mathrm{~mm}, 6 \mathrm{~mm}$ to $9 \mathrm{~mm}$ and $\geq 10 \mathrm{~mm}$ ) or location (right, transverse, left colon). Polyps in CCE with corresponding polyps regarding size and/or location in $\mathrm{CC}$ were classified as true positive. Cases with no polyps at CCE and CC were classified as true negative. If CCE detected a polyp with no corresponding polyp at CC, this finding was classified as false positive for CCE. If CC detected a polyp that was not reported by CCE, this finding was classified as false negative for CCE.

As a secondary end point, a per-patient analysis was conducted to evaluate the accuracy of PillCam Colon 2 in identifying patients with any colonic polyps whatsoever. Patients without polyps at CC were classified as negative in the reference standard. A positive result was defined if CC detected $\geq 1$ polyp of any size. CCE results were reported 
TABLE 2

\section{Patient characteristics}

\begin{tabular}{lc}
\hline Age, years, mean (range) & $51(24-75)$ \\
Sex, male/female, $\mathrm{n} / \mathrm{n}$ & $14 / 10$ \\
Indications & $\mathbf{n}(\%)$ \\
\hline Colorectal cancer screening & - \\
Positive family history & $5(22)$ \\
No increased risk & $8(33)$ \\
Polyp surveillance & $7(29)$ \\
Suspected inflammatory bowel disease & $2(8)$ \\
Surveillance colonoscopy in ulcerative colitis & $2(8)$ \\
\hline
\end{tabular}

as positive if $\geq 1$ polyp of any size was identified, otherwise they were reported as negative. Definitions for true/false-positive/negative results had been assessed analogous to the per-findings analysis.

Statistical analysis was performed using SPSS version 11.5.1 (IBM Corporation, USA) for Windows (Microsoft Corporation, USA). For normally distributed quantitative data, the summary statistics were the mean, $\mathrm{SD}$ and the range shown as mean (SD, range) within the given values. Non-normally distributed data are presented as median (interquartile range). Sensitivity and specificity with their exact $95 \%$ CIs as well as the negative predictive value (NPV) and positive predictive value (PPV) were calculated.

\section{RESULTS}

In total, 24 patients (14 male, 10 female) with an average age of 51 years (range 24 to 75 years) were included in the present study. Seven (29\%) patients had undergone polypectomy in the past, five (22\%) had a positive family history for CRC, eight (33\%) underwent endoscopy for screening purposes, two (8\%) experienced diarrhea for more than two weeks and two $(8 \%)$ were scheduled for surveillance colonoscopy due to known ulcerative colitis (Table 2).

No technical difficulties that led to termination of the examinations occurred. All patients were able to swallow the capsule. The colon was reached in 23 of 24 CCEs. Twenty-three of 24 CCs were completed (including successful intubation of the ileum); one examination was terminated in the transverse colon due to unmanageable pain in the patient.

\section{Colon capsule egestion rate}

In 17 of $24(71 \%)$ patients, CCE was completed by capsule egestion within the battery lifespan. Egestion rates were 10 of 17 (59\%) within 6 h, 12 of $17(71 \%)$ within 8 h, 14 of 17 (82\%) within 10 h, 17 of $17(100 \%)$ within $>10$ h postingestion. The mean $( \pm$ SD) overall examination time for 17 completed CCEs was 07:05 $\pm 03: 49 \mathrm{~h}$ (range $02: 17 \mathrm{~h}$ to $16: 18 \mathrm{~h}$ ). The passage time for the separate sections of the intestine were 00:58 $\pm 01: 02 \mathrm{~h}(00: 06 \mathrm{~h}$ to $03: 50 \mathrm{~h})$ for the stomach, 01:46 $\pm 01: 36 \mathrm{~h}(00: 20 \mathrm{~h}$ to $07: 09 \mathrm{~h})$ for the $\mathrm{SB}$ and 05:15 $\pm 03: 38 \mathrm{~h}$ (01:06 h to $14: 13 \mathrm{~h})$ for the colon. In seven of 24 patients, the colon was incompletely visualized, with a mean working time of 11:16 $\pm 3: 20 \mathrm{~h}$ (range 9:21 h to 17:49 h), which was longer than CCEs with completed colon visualization. Due to the battery's lifespan, six of seven examinations were terminated before egestion (one CCE during passage of the transverse colon and all others during passage of the sigmoid colon). In a one patient, the capsule remained in the stomach for nearly $4 \mathrm{~h}$ and did not reach the colon thereafter, albeit with an examination and capsule working time of almost $11 \mathrm{~h}(10: 53 \mathrm{~h})$. This particular case was excluded from further analyses.

\section{Colon cleansing level}

CCE bowel preparation was evaluated individually for the various segments (eg, cecum, ascendens, transversum, descending, sigmoid/rectum). Overall, bowel cleansing was categorized as adequate (good or excellent) in $90.1 \%$ of patients. The percentage of adequately cleansed patients varied depending on the segment (cecum $82.4 \%$, ascending
TABLE 3

Colonic polyps at colon capsule endoscopy (CCE) compared with conventional colonoscopy (CC) in the per-findings analysis

\begin{tabular}{lcccc}
\hline & CC, $\mathbf{n}$ & CCE, $\mathbf{n}$ & Sensitivity, $\%$ & Specificity, $\%$ \\
\hline $\begin{array}{l}\text { Polyp size, mm } \\
<6\end{array}$ & 16 & 20 & 100 & 83.3 \\
$6-9$ & 17 & 14 & 72.2 & 90.9 \\
$\geq 10$ & 11 & 9 & 75 & 100 \\
$\quad$ Overall & 44 & 43 & 80.0 & 93.7 \\
Polyp location & & & & \\
$\quad$ Right colon & 12 & 12 & $75.0^{*}$ & 72.7 \\
Transverse & 10 & 9 & 90 & 100 \\
Left colon & 22 & 22 & 100 & 100 \\
Overall & 44 & 43 & 90.1 & 76.9 \\
\hline
\end{tabular}

*Polyps found at CCE were not identical to the polyps found at CC in every case (ie, not all polyps in the right colon detected in CCE could be verified using CC and vice versa). Therefore, the sensitivity was merely $75 \%$, although 12 polyps could be detected using each modality

colon $88.2 \%$, transverse colon $94.1 \%$, descending colon $93.3 \%$, sigmoid/ rectum $93.3 \%$ ).

\section{Adverse events}

One patient reported headache during preparation for the CCE procedure. No other adverse events were recorded during the CCE and the CC endoscopies. However, temporary transmission failures, resulting in a partial loss of frames, were recorded in four $(16.7 \%)$ early videos, with a mean duration of $23 \pm 13 \mathrm{~min}$ (range $7 \mathrm{~min}$ to $45 \mathrm{~min}$ ) mainly ( $\mathrm{n}=3[75 \%])$ after the capsule had already reached the rectum. In one patient, six gaps were found, two gaps were found in another and one gap was recorded in each of the remaining patients. After changing the standard sensor array placement, with one sensor on the patient's back above the right buttock, this problem was avoided in all subsequent procedures.

\section{Colonic findings}

CCE accuracy for detecting polyps (per-finding analysis): In six of 23 cases, both CC and CCE did not detect polyps (true negative). In the other 17 cases, 47 polyps were detected. Forty of 47 (85.1\%) polyps were apparent in both examinations (true positive). Locations were: cecum $(n=3)$, ascending $(n=6)$, transverse $(n=9)$, descending $(n=8)$, sigmoid colon $(n=10)$ and rectum $(n=4)$. Four $(8.5 \%)$ polyps were detected by CC but missed at CCE (false negative). These polyps had a size of $6 \mathrm{~mm}$ to $12 \mathrm{~mm}$ and were located in the transverse colon and the cecum. Three (6.4\%) polyps were detected by CCE: size $3 \mathrm{~mm}$ and $7 \mathrm{~mm}$, and $11 \mathrm{~mm}$ in the cecum or the ascending colon but not reconfirmed at CC (false positive). One of these three polyps $(3 \mathrm{~mm})$ was located in the cecum and could not be identified by CC even after unblinding of the endoscopist for this finding. However, three of the latter seven polyps were recorded in patients who had more than one polyp, which were all detected by both methods.

According to this per-finding analysis, CCE achieved an overall sensitivity of $90.9 \%$ (95\% CI $85 \%$ to $100 \%$ ) and a specificity of $67.6 \%$ ( $95 \%$ CI 36\% to 98\%) in the detection of any size polyp. Compared with CC, polyps were found by CCE with a PPV and NPV of $93.0 \%$ and $71.4 \%$, respectively. When sensitivity and specificity levels were considered according to subgroup (eg, size and polyp location), the individual percentage varied significantly (Table 3 ).

CCE accuracy for identifying patients as polyp carriers (per-patient analysis): At CC, a total of 16 of 23 (69.6\%) patients had $\geq 1$ polyp of any size. At least one polyp was identified by CCE in 14 of $23(60.8 \%)$ patients. In $13(56.5 \%)$ patients, CCE-positive patients were reconfirmed by CC (true positive). In six (26.1\%) patients, CCE and CC detected no polyp (true negative). In a single CCE-positive patient 


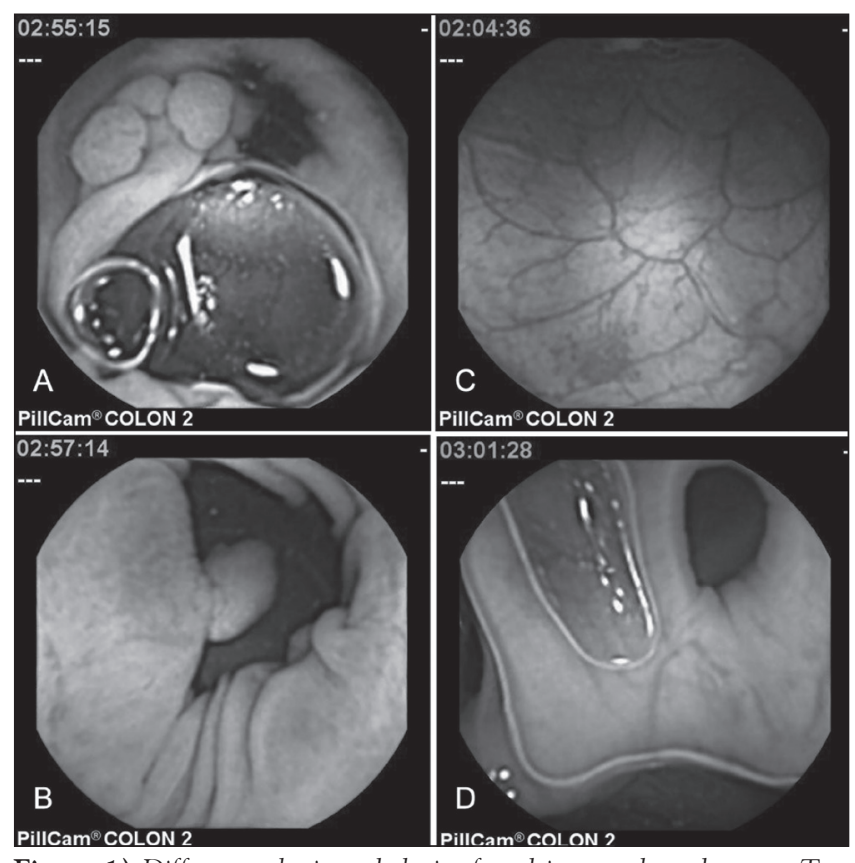

Figure 1) Different colonic pathologies found in capsule endoscopy. Two colorectal polyps measuring $17 \mathrm{~mm}$ (A) and $10 \mathrm{~mm}$ (B), an angiodysplasia (C) and a diverticulum (D)

(4.3\%) no polyp was recorded at CC (false positive). In three (13.1\%) CCE-negative patients, CC identified at least one polyp (false negative).

According to these data, in the per-patient analysis, CCE could identify patients with polyps regardless of the number or size with a sensitivity of $81.5 \%$ (95\% CI $62 \%$ to $100 \%$ ) and a specificity of $85.7 \%$ (95\% CI $60 \%$ to $100 \%$ ). The PPV of CCE with respect to identifying patients with colorectal polyps was $92.9 \%$; the NPV was $67 \%$.

\section{Nonpolyp colonic findings}

In addition to polyps (Figure 1A/B), CCE detected additional colonic lesions such as an angiodysplasia in the ascending colon (Figure 1C) as well as diverticulae (Figure 1D) in four patients (17\%) and a severe inflammation due to ulcerative colitis in one patient each (4\%). These lesions were reconfirmed by flexible colonoscopy in all cases.

\section{Extracolonic findings}

In 22 of $24(92 \%)$ cases, CCE presented a median of 17 (range one to $685)$ frames of the esophagus. Only in two (8\%) cases, esophageal transit was abrupt without recording any images. The $Z$ line was visible in 19 of 24 patients (79\%) in $4 \pm 3$ (range one to 10 ) frames on average (Figure 2A). Excellent or good cleanliness of the esophagus and the $\mathrm{Z}$ line were recorded in 20 of $22(91 \%)$ and 19 of 19 (100\%), respectively. Cleanliness was reduced due to bubbles/saliva in only a minority of patients. Pathological findings, such as esophagitis $\left(I^{\circ}: n=4, I^{\circ}\right.$ : $\mathrm{n}=1$ ), suspected Barrett's esophagus (COM1 according to the Prague classification) and varices ( $\mathrm{I}^{\circ}$ according to Sarin's classification) due to portal hypertension, were recorded in seven of 24 patients (29\%).

The gastric video segment had a mean duration of $58 \mathrm{~min}$. Due to the battery-saving sleep mode and automatic capsule activation after detection of SB mucosa, the pylorus was visible only in exceptional cases (four of 24 [17\%]). Gastric cleanliness was limited in most cases (20 of 24 [84\%]) due to saliva and bubbles. In nine of 24 (38\%) patients, pathological findings, such as mucosal erythema, erosions and portal hypertensive gastropathy, were recorded.

The mean length of SB video was 1:46 h. Analogous to the pylorus, Vater's papilla (Figure 2B) was visible in the same four (17\%) cases. SB cleanliness was adequate (excellent or good) in 20 of 24 cases (84\%) and inadequate (moderate or poor) in four of 24 (16\%) cases. In 14 of
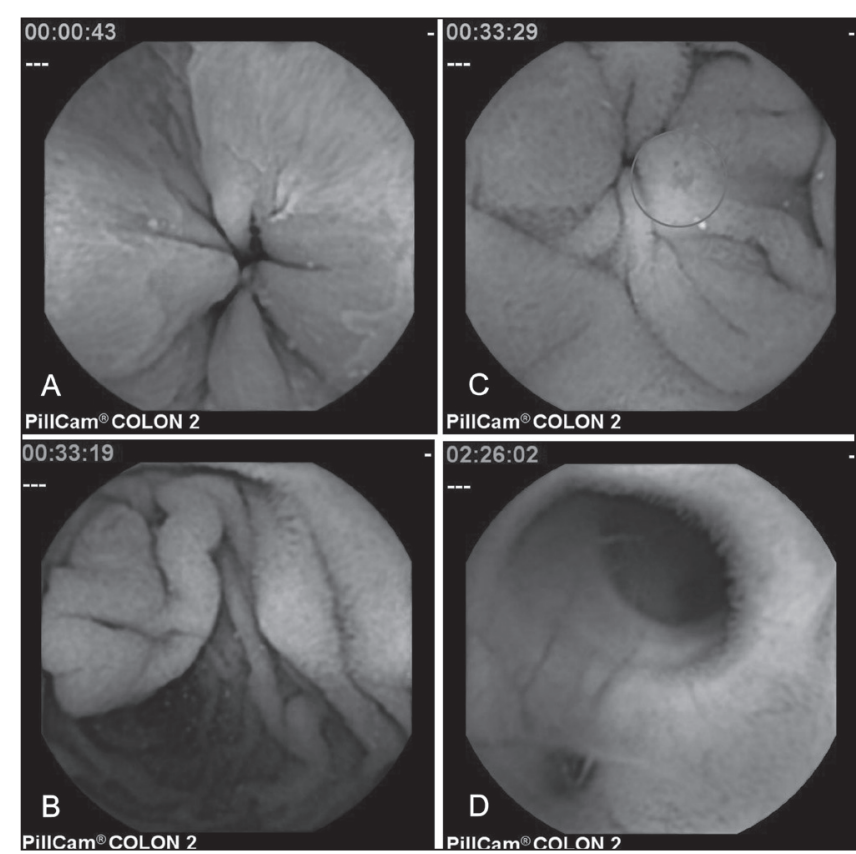

02:26:02

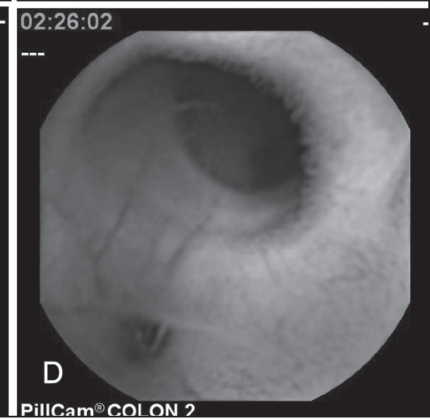

Figure 2) Extracolonic landmarks and findings. Z-line (A); papilla of Vater (B); small bowel angiodysplasia (C); ileic diverticulum (D)

$24(58 \%)$ patients, pathological findings, such as angiodysplasias (Figure $2 \mathrm{C}$ ), erosions, ulcerations, strictures, diverticula orifices (Figure 2D) or polyps, were recorded within the SB (Table 4).

\section{DISCUSSION}

In the present study, colonic findings using PillCam Colon 2 CCE and flexible CC were compared. As a single-centre study, the present analysis offers the advantage of a limited number of physicians with expertise in capsule video reading and flexible colonoscopy. According to our data, CCE afforded good sensitivity and specificity ( $>81 \%$ and $85 \%$, respectively) in identifying patients with polyps regardless of polyp size (per-patient analysis). These data are similar to previously published rates for sensitivity $(89 \%$ and $88 \%)$ and specificity $(76 \%$ and $89 \%$ ) found in other studies involving the second-generation PillCam Colon for polyps $\geq 6 \mathrm{~mm}$ and $\geq 10 \mathrm{~mm}$, respectively $(7,8)$, showing a clear advantage over the first-generation model, which had sensitivity rates of between $60 \%$ and $72 \%$ (11). Apart from the improved angle of vision of the two lenses (from $156^{\circ}$ to $172^{\circ}$ ), the increase in sensitivity may be very likely due to the increased and automatically steered variability of the frame rate according to the velocity of the capsule motion (12). Nine of the polyps were recorded in $\leq 5$ images. These may have been missed using the lower frame rate of first-generation CCE. Another major factor influencing the rate of polyp detection is the level of bowel preparation (13). Similar to previous studies $(7,8)$, our data show an adequate preparation in $90.1 \%$ of all evaluated segments. The overall egestion rate of $71 \%$ was slightly lower than in previous studies $(7,8)$, which may be explained by the smaller number of patients included. In our patient cohort, cleansing was not as complete in patients with missing egestion. Therefore, slower peristalsis may have hampered both bowel preparation and capsule propulsion. The only adverse event recorded in our study was one patient who experienced headache during preparation for CCE. Overall, the standardized cleansing regimen, including sodium phosphate for capsule propulsion, proved to be safe and effective (14).

Additionally, we compared CCE and CC polyp-by-polyp with respect to size and location. This per-findings analysis showed a capsule sensitivity and specificity for polyp identification of $91.0 \%$ and $76.9 \%$, respectively. The apparently suboptimal specificity of CCE mainly arises from the small number of true-negative capsule videos as a result of our 
TABLE 4

Extracolonic capsule endoscopy findings

\begin{tabular}{|c|c|c|c|c|c|c|}
\hline Intestine & Video length (range) & $\begin{array}{l}\text { Presentation of } \\
\text { anatomical landmarks, } n(\%)\end{array}$ & $\begin{array}{l}\text { Degree of } \\
\text { cleanliness* }\end{array}$ & $n(\%)$ & Capsule findings & $n(\%)$ \\
\hline Esophagus & $58 \pm 138$ min $(0-685)$ frames & $\begin{array}{l}Z \text { line: } \\
\text { Yes: } 19 \text { (79) }\end{array}$ & $1^{\circ}$ & $9(38)$ & Esophagitis & $5(21)$ \\
\hline & & & $11^{\circ}$ & $11(46)$ & Suspected Barrett's esophagus & $1(4)$ \\
\hline & & & $1111^{\circ}$ & $4(16)$ & Varices & $1(4)$ \\
\hline & & & $\mathrm{IV}^{\circ}$ & - & & \\
\hline \multirow{2}{*}{ Stomach } & & No: $20(83)$ & $1110^{\circ}$ & $3(13)$ & Portal hypertensive gastropathy & $1(4)$ \\
\hline & & & $\mathrm{IV}^{\circ}$ & - & & \\
\hline \multirow[t]{4}{*}{ Small bowel } & $01: 46 \pm 01: 36$ h $(00: 20 h-07: 09 h)$ & Papilla of Vater: & $1^{\circ}$ & $9(38)$ & Angiodysplasia & $5(21)$ \\
\hline & & Yes: 4 (17) & ${ }^{\circ}{ }^{\circ}$ & $11(46)$ & Erosion & $7(29)$ \\
\hline & & No: $20(83)$ & $1110^{\circ}$ & $4(16)$ & Diverticulae & $3(13)$ \\
\hline & & & & & Brunner's gland tumours & $2(8)$ \\
\hline
\end{tabular}

${ }^{*} I^{\circ}=$ Excellent $; I^{\circ}=$ Good $; I I I^{\circ}=$ Moderate $; I V^{\circ}=$ Poor

polyp-enriched study population. In a screening population, a higher specificity for CCE might be expected. Additionally, false-positive findings in CCE hamper its specificity. However, as previously described, CC may be an imperfect reference standard, with reduced sensitivity especially for polyps $<9 \mathrm{~mm}$ in size $(15,16)$. In fact, it cannot be ruled out that false-positive findings at CCE were false-negative findings at CC. Further studies with different methodology (eg, unblinding colonoscopists) are necessary to evaluate the true specificity of CCE. However, even after unblinding, detection of polyps at CC previously identified at CCE cannot be expected in every case due to a limited flexibility and angular field of the endoscope as well as air insufflation, as occurred in one case in our series.

All CC-proven polyps missed during CCE were located either in the right or the transverse colon. A similar distribution of location of missed polyps was reported earlier by Spada et al (8). This result is especially frustrating because it confirms problems in detecting polyps and cancerous lesions in the right colon, similar to CC (17).

Three polyps detected at CC had been missed at CCE in patients with additional polyps identified by both techniques. Despite the lower per-findings sensitivity in these cases, the per-patient sensitivity was unaffected because CCE could, in fact, identify those patients as polyp carriers. Undoubtedly, this is an important secondary aim of CCE and its efficacy regarding this issue is highlighted by the notable PPV of CCE compared with flexible colonoscopy in the per-patient analysis. However, concerning CCE as a CRC screening tool, the NPV will be even more important. The limited NPV of CCE appears to challenge its value in this respect. However, NPV and PPV are highly affected by prevalence of findings and, similar to previous studies, our patient cohort was polyp enriched. Therefore, the low NPV may be the result of an under-represented CRC screening population among the study attendees and must be re-evaluated in future studies.

The cost effectiveness of CRC screening depends on three main criteria: adenoma detection rate; financial expenditure of the screening tool; and adherence to the screening program. The latter can be increased by CCE as previously published (5). Whether the high costs - depending on the national health care system - and the limited adenoma detection rate of CCE are compensated by the increased compliance to CRC screening has not, to date, been proven $(18,19)$.

Apart from colonic polyps, several other colonic pathologies were recorded, such as ulcerative colitis, diverticulae or angiodysplasias, which were reconfirmed at $\mathrm{CC}$ in every case. Ulcerative colitis imaging of colonic mucosa by CCE has been previously evaluated (20); the lack of air insufflation and avoidance of the shear forces executed by the endoscope may reduce the risk of reinjury during evaluation of the mucosal healing under therapy.

CCE is also able to effectively visualize esophageal, gastric and SB pathologies. Similar to PillCam Eso (21), frames of the Z line were present in $>90 \%$ of the videos despite a capsule administration in a sedentary position and without a specific ingestion protocol. Even cleansing was excellent, with little bubbles/saliva having no or only a minor negative effect on $\mathrm{Z}$ line images.

In contrast, due to the sleep mode, presentation of the pylorus was rare and, consequently, gastric appraisal was incomplete. Additionally, cleanliness was limited in most cases, and the lack of a steering device and air insufflation leads to a reduced ability to examine the entire gastric mucosa. Nevertheless, pathological findings, such as mucosal erythema, erosions and portal hypertensive gastropathy, were recorded in more than one-third of the patients. Therefore, once capsule steering (which has been investigated in recent studies [22]) becomes available, re-evaluation of gastric imaging using CCE may be warranted.

$\mathrm{SB}$ visualization was excellent and cleanliness was adequate in the majority (84\%) of the patients. The ileocecal valve was visualized in all videos. If CCE was activated within the stomach, the papilla of Vater was visible in every case. Although inconsequential to our analysis, SB findings were recorded in more than one-half of the patients. The accuracy in visualizing frames of anatomical landmarks illustrates that doubling the number of optical devices and the movement-adapted frame rate of CCE optimizes visualization of SB mucosa. Therefore, with adequate cleansing and appropriate application protocols, indications for CCE may be expanded. It may be useful to evaluate the extent of Crohn disease to facilitate the classification of indeterminate colitis and, furthermore, in the screening of patients with familial adenomatous polyposis or Peutz-Jeghers syndrome.

Similar to virtual colonoscopy, CCE offers the benefit of earlier diagnosis of clinically significant extracolonic - yet gastrointestinal lesions in a one-step assessment, possibly decreasing patients' morbidity or mortality. On the other hand, extracolonic gastointestinal findings may also lead to additional diagnostic evaluation or intervention leading to patient anxiety, morbidity and increased health care costs, once again challenging the cost effectiveness of CCE $(23,24)$. Therefore, further analyses will be necessary to evaluate the impact of $\mathrm{CCE}$ on extracolonic gastrointestinal pathologies. 


\section{SUMMARY}

CCE is technically feasible and safe. The per-patient and per-finding analysis demonstrate a viable sensitivity and moderate specificity of the new generation of the PillCam Colon 2 in polyp detection compared with the current gold standard of flexible colonoscopy. However, the limited NPV as well as high cost of CCE challenge its application as a screening tool at present. Because extracolonic landmarks and findings are effectively visualized, indications for CCE may be extended, especially with respect to inflammatory bowel diseases and polyposis syndromes.

DISCLOSURES: The capsule endsocopes used in this study were supplied by Given Imaging, Israel. The work originated from the Department of Gastroenterology, University of Erlangen, Erlangen, Germany.

\section{REFERENCES}

1. International Agency for Research on Cancer. WHO and International Association of cancer registries. In: Parkin DM, Whelan SL, Ferlay J, Raymond L, Yung J, eds. Cancer Incidence in Five Continents. Lyon: IARC Scientific Publications, 1997.

2. Atkin WS, Edwards R, Kralj-Hans I, et al. UK Flexible Sigmoidoscopy Trial Investigators. Once-only flexible sigmoidoscopy screening in prevention of colorectal cancer: A multicentre randomised controlled trial. Lancet 2010;8:1624-33.

3. Knöpnadel J, Altenhofen L, Brenner G. Epidemiologic and health economic significance of colorectal cancers in Germany. Internist (Berl) 2003;44:268-74;276-7.

4. Lisi D, Hassan C, Crespi M, AMOD Study Group. Participation in colorectal cancer screening with FOBT and colonoscopy: An Italian, multicentre, randomized population study. Dig Liver Dis 2010;42:371-6.

5. Groth S, Krause H, Behrendt R, et al. Capsule colonoscopy increases uptake of colorectal cancer screening. BMC Gastroenterology 2012;12:80.

6. Spada C, Hassan C, Marmo R, et al. Meta-analysis shows colon capsule endoscopy is effective in detecting colorectal polyps. Clin Gastroenterol Hepatol 2010;8:516-22.

7. Eliakim R, Yassin K, Niv Y, et al. Prospective multicenter performance evaluation of the second-generation colon capsule compared with colonoscopy. Endoscopy 2009;41:1026-31.

8. Spada C, Hassan C, Munoz-Navas M, et al. Second-generation colon capsule endoscopy compared with colonoscopy. Gastrointest Endosc 2011;74:581-9.

9. Schoofs N, Devière J, Van Gossum A. PillCam Colon capsule endoscopy compared with colonoscopy for colorectal tumor diagnosis: A prospective pilot study. Endoscopy 2006;38:971-7.
10. Leighton JA, Rex DK. A grading scale to evaluate colon cleansing for the PillCam COLON capsule: A reliability study. Endoscopy 2011:43:123-7.

11. Riccioni ME, Urgesi R, Cianci R, Bizzotto A, Spada C, Costamagna G. Colon capsule endoscopy: Advantages, limitations and expectations. Which novelties? World J Gastrointest Endosc 2012;4:99-107.

12. Adler SN, Metzger YC. PillCam COLON capsule endoscopy: Recent advances and new insights. Therap Adv Gastroenterol 2011:4:265-8.

13. Van Gossum A, Munoz-Navas M, Fernandez-Urien I, et al. Capsule endoscopy versus colonoscopy for the detection of polyps and cancer. N Engl J Med 2009;361:264-70.

14. Sieg A. Capsule endoscopy compared with conventional colonoscopy for detection of colorectal neoplasms. World J Gastrointest Endosc 2011;3:81-5.

15. Hixon LJ, Fennerty MB, Sampliner RE, et al. Prospective blinded trial of the colonoscopic miss-rate of large colorectal polyps. Gastrointest Endosc 1991;37:125-7.

16. Rex DK, Cutler CS, Lemmel GT, et al. Colonoscopic miss rates of adenomas determined by back to back colonoscopies. Gastroenterology 1997;112:24-8.

17. Brenner H, Hoffmeister M, Arndt V, Stegmaier C, Altenhofen L, Haug U. Protection from right-and left-sided colorectal neoplasms after colonoscopy: Population-based study. J Natl Cancer Inst 2010;102:89-95.

18. Sonnenberg, A, Delcó F, Inadomi JM, Cost-effectiveness of colonoscopy in screening for colorectal Cancer. Ann Intern Med 2000;133:573-84.

19. Hassan C, Zullo A, Winn S, Morini S. Cost-effectiveness of capsule endoscopy in screening for colorectal cancer. Endoscopy 2008;40:414-21.

20. Sung J, Ho KY, Chiu HM, Ching J, Travis S, Peled R. The use of Pillcam Colon in assessing mucosal inflammation in ulcerative colitis: a multicenter study. Endoscopy 2012;44:754-8.

21. Gralnek IM, Adler SN, Yassin K, Koslowsky B, Metzger Y, Eliakim R. Detecting esophageal disease with second-generation capsule endoscopy: Initial evaluation of the PillCam ESO 2. Endoscopy 2008;40:275-9.

22. Capri F, Kastelein N, Talcott M, Pappone C. Magnetically controllable gastrointestinal steering of video capsules. IEEE Trans Biomed Eng 2011;58:231-4.

23. Yee J, Sadda S, Aslam R, Yeh B. Extracolonic findings at CT colonography. Gastrointest Endosc Clin N Am 2010;20:305-22.

24. Xiong T, McEvoy K, Morton DG, Halligan S, Lilford RJ. Resources and costs associated with incidental extracolonic findings from CT colonogaphy: A study in a symptomatic population. Br J Radiol 2006;79:948-61. 


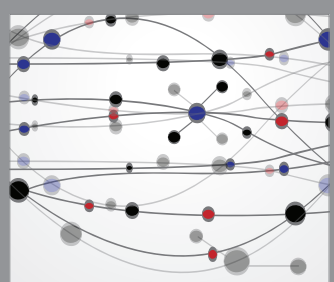

The Scientific World Journal
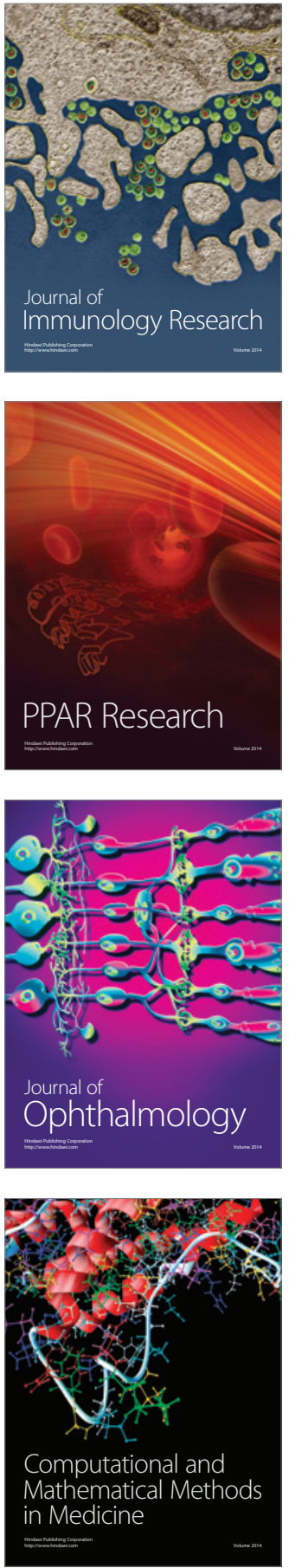

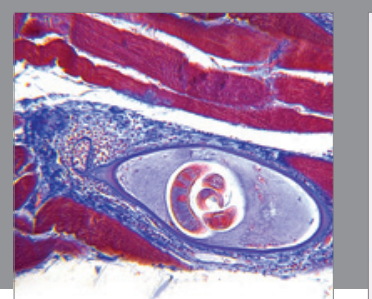

Gastroenterology Research and Practice

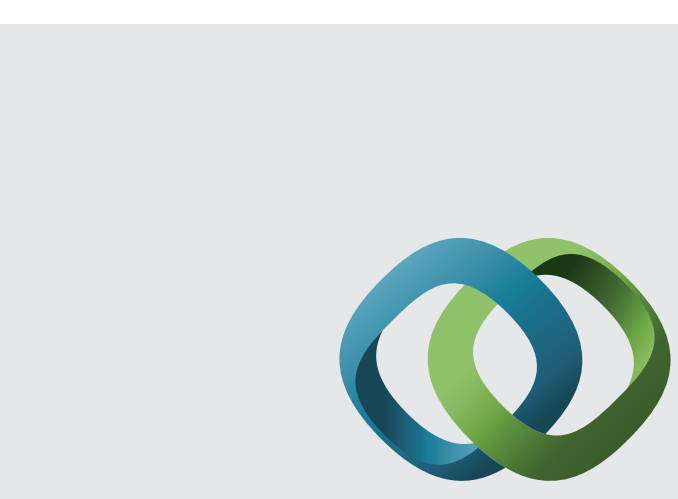

\section{Hindawi}

Submit your manuscripts at

http://www.hindawi.com
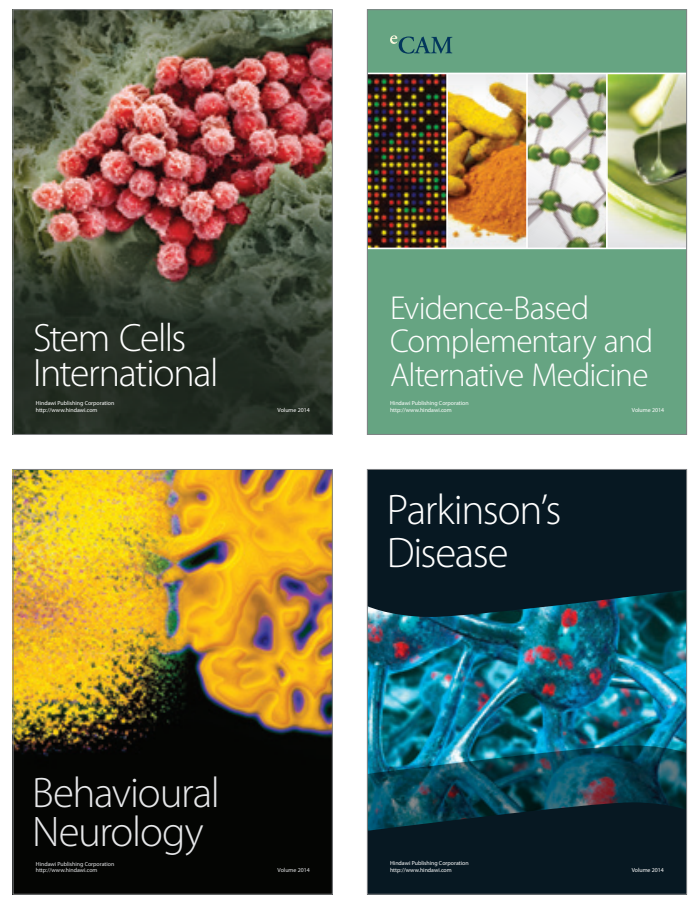
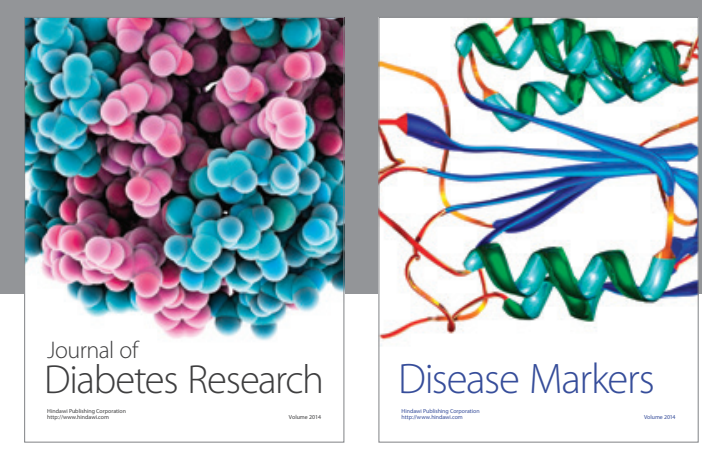

Disease Markers
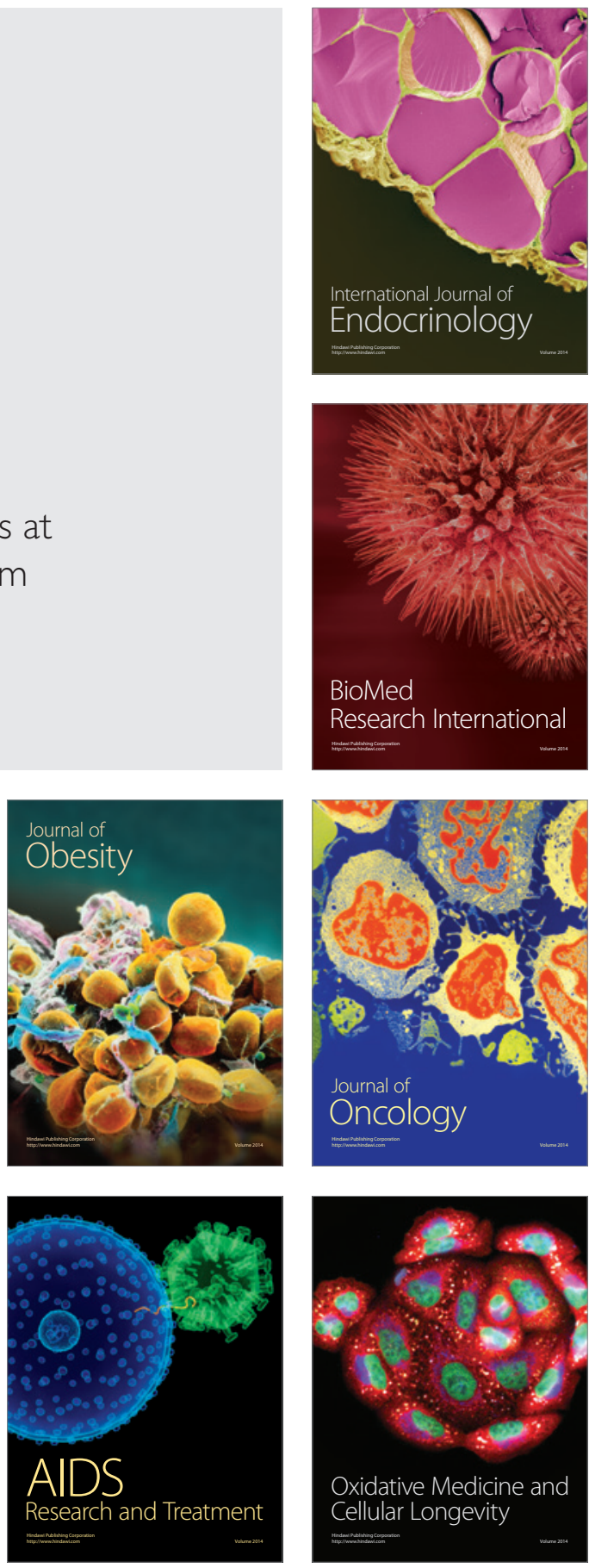